\title{
Thapsigargin promotes colorectal cancer cell migration through upregulation of IncRNA MALAT1
}

\author{
XIA JIANG ${ }^{1}$, DONGYUN LI ${ }^{1}$, GUIQI WANG ${ }^{1}$, JUE LIU ${ }^{1,2}$, XINGKAI SU ${ }^{1}$, WEIFANG YU ${ }^{3}$, \\ YUANYUAN WANG ${ }^{1}$, CONGJIE ZHAI ${ }^{1}$, YUEGENG LIU ${ }^{1}$ and ZENGREN ZHAO ${ }^{1}$ \\ ${ }^{1}$ Department of General Surgery, Hebei Key Laboratory of Colorectal Cancer Precision Diagnosis and Treatment, \\ The First Hospital of Hebei Medical University, Shijiazhuang, Hebei 050031; ${ }^{2}$ Department of Criminal Technology, \\ Xinji Municipal Public Security Bureau, Xinji, Hebei 052360; ${ }^{3}$ Department of Endoscopy Center, \\ The First Hospital of Hebei Medical University, Shijiazhuang, Hebei 050031, P.R. China
}

Received August 26, 2019; Accepted January 16, 2020

DOI: 10.3892/or.2020.7502

\begin{abstract}
Colorectal cancer (CRC) is the third most common tumor in the world; however, the role and mechanism of endoplasmic reticulum (ER) stress in CRC metastasis remains largely unclear. Metastasis-associated lung adenocarcinoma transcript 1 (MALAT1) is a long non-coding RNA (lncRNA), which has previously been associated with CRC metastasis. It has been suggested that ER stress pathways regulate lncRNA expression; however, the effect of ER stress on MALAT1 expression in cancer is unknown. The present study aimed to investigate the relationship between ER stress pathways, MALAT1 expression and cell migration in CRC cells. ER stress was induced by thapsigargin (TG); low dose TG induced the migration of HT29 and HCT116 cells, but not SW1116 and SW620 cells. This effect was associated with increased expression levels of MALAT1, as the knockdown of MALAT1 prevented TG-induced cell migration. TG-induced MALAT1 expression was associated with inositol-requiring enzyme 1 (IRE1) expression and activation of the protein kinase R (PKR)-like ER kinase (PERK) signaling pathway. $\mathrm{X}$-box-binding protein 1 (XBP1) and activating transcription factor 4 (ATF4) binding sites were predicted to be located in the MALAT1 gene promoter regions and the expression of MALAT1 was positively associated with XBP1 and ATF4 expression levels in CRC tissue samples. Thus, these findings indicated that ER stress may promote the migration of CRC
\end{abstract}

Correspondence to: Professor Zengren Zhao or Dr Xia Jiang, Department of General Surgery, Hebei Key Laboratory of Colorectal Cancer Precision Diagnosis and Treatment, The First Hospital of Hebei Medical University, 89 Donggang Road, Shijiazhuang, Hebei 050031, P.R. China

E-mail: zzr-doctor@163.com

E-mail: jxia925@yahoo.co.jp

Key words: colorectal cancer, endoplasmic reticulum stress, cell migration, thapsigargin, metastasis-associated lung adenocarcinoma transcript 1 , unfolded protein response cells and contribute to the progression of CRC through the activation of the IRE1/XBP1 and PERK/eIF2 $\alpha / A T F 4$ signaling pathways. In conclusion, to the best of our knowledge, this study is the first report that lncRNA MALAT1 expression is regulated by the IRE1/XBP1 pathway in CRC.

\section{Introduction}

Colorectal cancer (CRC) is one of the most common cancers in world, ranking third overall in terms of incidence rates and second in terms of mortality rates, with $>1.8$ million new cases and 861,663 death cases reported worldwide in 2018 (1). Both the incidence and mortality rates of CRC have increased in China in the past decade; in 2018, the latest epidemiological statistics of Globocan reported that the incidence and mortality rates of CRC were 23.7 and 10.9, respectively, per 100,000 (1). Unfortunately, in the majority of patients, CRC is diagnosed at an advanced stage, following the metastasis to adjacent or distant organs (2); however, the mechanisms regulating metastasis in CRC remain largely unknown. Therefore, there is an urgent requirement to identify the molecular mechanisms of CRC metastasis to provide novel therapeutic targets for the treatment of the disease.

Endoplasmic reticulum (ER) stress is reportedly involved in CRC metastasis (3). The ER has established unique signaling pathways to combat stress, which are collectively known as the unfolded protein response (UPR) (4); glucose regulated protein 78 (GRP78) initiates the UPR and it has been demonstrated to promote the resistance of CRC cells to oxaliplatin (5). Depending on the status of GRP78, the ER transmembrane sensors, inositol-requiring enzyme 1 (IRE1), protein kinase RNA activated-like ER kinase (PERK) and activating transcription factor 6 (ATF6) are also involved in initiating signaling pathways involved in the UPR (4). IRE1 catalyzes a unique splicing event that removes 26 nucleotides from X-box-binding protein 1 (XBP1) mRNA, and the activation of the IRE1/XBP1 pathway has been observed to induce CRC cell invasion (3); however, the mechanism underlying the IRE1/XBP1 pathway induction of CRC cell invasion is not fully elucidated. The phosphorylation of PERK activates the downstream signaling molecule, $\alpha$-subunit of eukaryotic 
initiation factor-2 (eIF $2 \alpha$ ), which effectively inhibits protein synthesis (4), and has been associated with the hypoxia-induced metastasis of cervical cancer (6). Finally, the proteolytic processing of ATF6 activates the ATF6 pathway, and ATF6 activation was reported to be involved in pancreatic cancer stem cell migration (7). However, the roles of the PERK/eIF2 $\alpha$ and ATF6 pathway in CRC migration are unknown. In the present study, thapsigargin (TG) was used as an ER stress inducer to irreversibly inhibit the sarco/ER $\mathrm{Ca}^{2+}$ ATPase and promote rapid ER $\mathrm{Ca}^{2+}$ depletion (8).

Long non-coding RNAs (lncRNAs) are non-coding transcripts of $>200$ nucleotides in length and certain lncRNAs serve important roles in CRC metastasis $(9,10)$. Metastasis-associated lung adenocarcinoma transcript 1 (MALAT1), also known as nuclear enriched abundant transcript 2 or LINC00047, is a lncRNA (11). MALAT1 is found to be overexpressed in colorectal cancer patients (12) and multiple studies have reported an association between MALAT1 expression and CRC metastasis $(9,13)$. The first study demonstrating the UPR-induced regulation of lncRNA expression was in a study of the flavivirus infection, whereby MALAT1 expression was increased through the PERK pathway of the UPR (14). However, the mechanisms underlying increased MALAT1 expression levels in CRC are not clear, in addition to whether the UPR pathway is involved in upregulating MALAT1 expression in CRC. It is hypothesized that the ER stress pathway regulates MALAT1 expression in $\mathrm{CRC}$; thus, the present study aimed to identify the association between the ER stress pathway, MALAT1 expression and cell migration in CRC, in addition to elucidating the roles of ER stress in CRC development.

\section{Materials and methods}

Patient studies. The present study was approved by the Ethics Committee of The First Hospital of Hebei Medical University (no. 2016004). Written informed consent prior to the study was obtained from all patients $(n=38 ; 18$ males, 20 females; average age $=61.5$ years). Patients were informed that they could withdraw from study participation at any time. Thirty-eight CRC tissue samples were collected from the First Hospital of Hebei Medical University between October 2016 and March 2017. After surgical removal, tissues were immediately frozen in liquid nitrogen then immediately stored in a freezer at $-80^{\circ} \mathrm{C}$. Patients had not received local or systemic treatment prior to the operation. The pathological diagnosis of all cancer tissue samples was adenocarcinoma and the clinicopathological features of patients are presented in Table I.

Reagents and plasmids. TG, a non-competitive inhibitor of the sarco/ER $\mathrm{Ca}^{2+}$ ATPase that promotes rapid ER $\mathrm{Ca}^{2+}$ depletion and the elevation of cytoplasmic $\mathrm{Ca}^{2+}$ concentrations to induce ER stress (8), was purchased from BioVision, Inc. The inhibitors, $4 \mu 8 \mathrm{C}$ (cat. no. S7272; IRE1/XBP1 pathway inhibitor, $1 \mu \mathrm{M}$ ), GSK2606414 (cat. no. S7307; PERK/eIF2 $\alpha /$ ATF4 pathway inhibitor, $1 \mu \mathrm{M}$ ) and AEBSF (cat. no. S7378; ATF6 pathway inhibitor, $0.3 \mu \mathrm{M}$ ), were purchased from Selleck Chemicals; anti-GRP78 (product no. 3177), anti-eIF2 $\alpha$ (product no. 5324) and anti-phospho-eIF2 $\alpha$ (product no. 3398) primary antibodies were obtained from Cell Signaling Technology, Inc.;
anti-XBP1 (product code ab198999) and anti-ATF6 (product code ab122897) primary antibodies were purchased from Abcam; the anti-ATF4 primary antibody (WL02330) was purchased from Wanleibio Co., Ltd.; the anti- $\beta$-actin primary antibody (cat. no. 60008-1-Ig) was purchased from Wuhan Sanying Biotechnology (ProteinTech Group, Inc.); and secondary antibodies (anti-mouse IgG cat no. A23910; anti-rabbit IgG catalogue no: A23720) were purchased from Abbkine Scientific Co., Ltd. All primers and small interfering RNAs (siRNAs) were synthesized and purchased from Sangon Biotech Co., Ltd.

Cell culture and reagents. The human CRC cell line HCT116 was obtained from Professor Xiaofeng Sun at the Division of Oncology, Department of Clinical and Experimental Medicine, Linköping University, Sweden. SW620, SW1116 and HT29 cells were obtained from Professor Jun Yu at the Department of Medicine and Therapeutics, The Chinese University of Hong Kong, Hong Kong. HCT116 and HT29 cells were cultured in McCoy's 5A medium (Gibco; Thermo Fisher Scientific, Inc.), and SW620 and SW1116 cells were cultured in DMEM (Gibco; Thermo Fisher Scientific, Inc.), supplemented with $10 \%$ FBS (Gibco; Thermo Fisher Scientific, Inc.) and $1 \%$ penicillin-streptomycin (Invitrogen; Thermo Fisher Scientific, Inc.). All cells were maintained in a humidified atmosphere at $37^{\circ} \mathrm{C}$ and $5 \% \mathrm{CO}_{2}$.

Cell Counting Kit-8 assay. Five thousands cells were seeded into 96-well plates and treated with TG $(0-10 \mu \mathrm{M})$ for $24 \mathrm{~h}$ at $37^{\circ} \mathrm{C}$. Following incubation, $10 \mu \mathrm{lCCK}-8$ reagent (Dojindo Molecular Technologies, Inc.) was added to each well, according to the manufacturer's protocol. Following incubation for $2 \mathrm{~h}$, the absorbance was determined using a Promega GloMax Luminescence detector, with each experiment performed in triplicate.

Reverse transcription-quantitative PCR (RT-qPCR). Total RNA was extracted from frozen tissues $(\sim 50 \mu \mathrm{g})$ using TRIzol ${ }^{\circledR}$ reagent (Invitrogen; Thermo Fisher Scientific, Inc.), according to the manufacturer's protocol, and subsequently resuspended in $50 \mu \mathrm{l}$ nuclease-free water. A total of $1 \mu \mathrm{g}$ RNA was reverse-transcribed into cDNA using the PrimeScript RT kit (Takara Bio Inc., RT temperature protocol: $37^{\circ} \mathrm{C}$ for $15 \mathrm{~min}$, $85^{\circ} \mathrm{C}$ for $\left.5 \mathrm{sec}\right)$. qPCR was subsequently performed using the Power SYBR ${ }^{\circledR}$ Green Master mix (Applied Biosystems; Thermo Fisher Scientific, Inc.), according to the manufacturer's protocol (step 1: $95^{\circ} \mathrm{C}$ for $10 \mathrm{~min}$; step 2 for 40 cycles: $95^{\circ} \mathrm{C}$ for $15 \mathrm{sec}, 60^{\circ} \mathrm{C}$ for $\left.1 \mathrm{~min}\right)$. The following primer pairs were used for the qPCR: MALAT1 forward, 5'-GTTACTCTTTTT TCCCCCCACCCCC-3' and reverse, 5'-TTCTCCCCCACC CTCTCTCTTCCCT-3'; GRP78 forward, 5'-GCCTGTATTTCT AGACCT GCC-3' and reverse, 5'-TTCATCTTGCCAGCCAGT TG-3'; XBP1 forward, 5'-AATGAAGTGAGGCCAGTGG-3' and reverse, 5'-TCAATACCGCCAGAATCCATG-3'; ATF4 forward, 5'-CСТTCACCTTCTTACAACCT-3' and reverse, 5'-GTAGTCTGGCTTCCTATCTC-3'; and GAPDH forward, 5'-ACCCACTCCTCCACCTTTG-3' and reverse, 5'-CTCTTG TGCTCTTGCTGGG-3' (15). The expression levels were normalized to the internal reference gene GAPDH and quantified using the $2^{-\Delta \Delta \mathrm{Cq}}$ method (16). 
Table I. Clinicopathological characteristics of patients with CRC.

\begin{tabular}{lc}
\hline Number of total patients & 38 \\
\hline Age, years & $61.5 \pm 15.2$ \\
Sex, number (\%) of patients & 18 \\
Male & 20 \\
Female & \\
Dukes, number (\%) of patients & 22 \\
A,B & 16 \\
C,D & \\
Depth of invasion, number (\%) of patients & 18 \\
T1,T2 & 20 \\
T3,T4 & \\
Location, number (\%) of patients & 17 \\
Colon & 21 \\
Rectum & \\
Lymph node metastasis, number (\%) of patients & 22 \\
Absent & 16 \\
Present & \\
Distant metastasis, number (\%) of patients & 32 \\
Absent & \\
Present & \\
Differentiation, number (\%) of patients & \\
Poor & \\
Moderate & \\
Well & \\
\hline
\end{tabular}

$\mathrm{CRC}$, colorectal cancer.

Migration assay. For migration assays, Transwell plates with $8-\mu \mathrm{m}$ pores (BD Biosciences) were used. Briefly, a total of $2 \times 10^{5}$ cells were plated in the upper chambers of Transwell plates in serum-free medium (McCoy's 5A or DMEM medium, supplemented with $1 \%$ penicillin-streptomycin). Culture medium (McCoy's 5A or DMEM medium, supplemented with $10 \%$ FBS and $1 \%$ penicillin-streptomycin) was plated in the lower chambers. Following incubation at $37^{\circ} \mathrm{C}$ for $24 \mathrm{~h}$, the non-invasive cells remaining in the upper chamber of the Transwell plate were removed with a cotton swab. Migratory cells were stained with a Diff-Quick stain kit according to the manufacturer's protocol and counted using a light microscope (magnification, x100).

Western blotting. Following $24 \mathrm{~h}$ of $0.01 \mu \mathrm{M}$ TG treatment, total protein was extracted from $10^{6}$ cells using an SDS sample buffer $[50 \mathrm{mM}$ Tris- $\mathrm{HCl}, 2 \% \mathrm{SDS}, 1 \%$ glycerol, $6 \% \beta$-mercaptoethanol, $1 \%$ protease inhibitor cocktail (cat. no. HY-K0010; MCE)] and processed for western blotting analysis as previously described (17). Briefly, 5-10 $\mu$ g proteins (measured by BCA protein assay kit and detected by Promega Glomax Luminometer) were separated via 10\% SDS-PAGE and separated proteins were transferred onto a PVDF membrane (EMD Millipore). The membrane was blocked

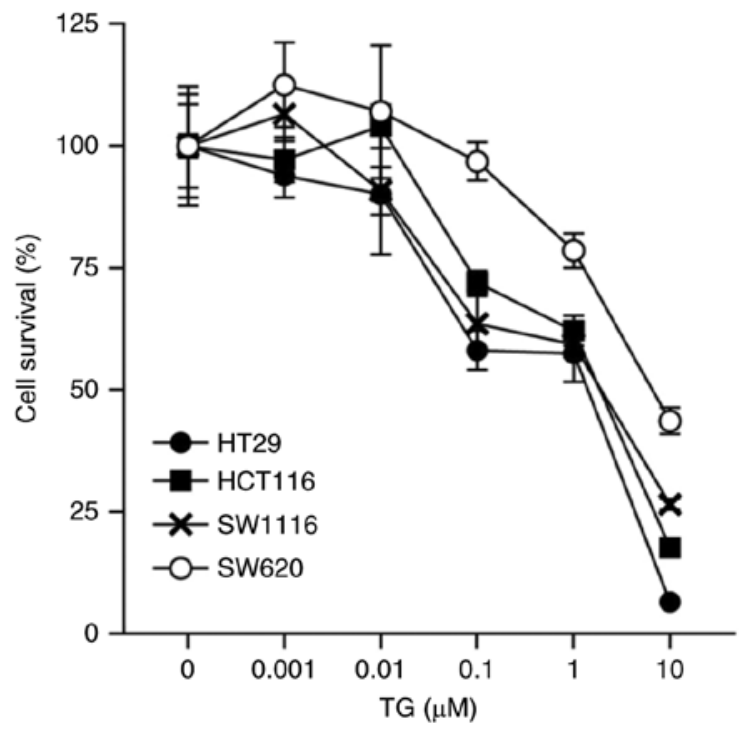

Figure 1. Effects of TG on cell viability in human colorectal cancer cell lines. Cell viability was determined using a Cell Counting Kit- 8 assay following treatment of cells with $0-10 \mu \mathrm{M}$ TG for $24 \mathrm{~h}$. Tests were performed in triplicate and data are presented as the mean \pm SD. TG, thapsigargin.

(5\% skim milk at $4^{\circ} \mathrm{C}$ overnight) and probed $\left(4^{\circ} \mathrm{C}\right.$ overnight) with the following primary antibodies: Anti-GRP78 (1:1,000), anti-eIF2 $\alpha(1: 1,000)$, anti-phospho-eIF2 $\alpha(1: 1,000)$, anti-XBP1 (1:350), anti-ATF6 (1:500), anti-ATF4 (1:500) and anti- $\beta$-actin $(1: 3,500)$. Following the primary antibody incubation, the membrane was washed with $1 \mathrm{X}$ TBST and incubated at room temperature with DyLight fluorescent dyes-conjugated secondary antibodies $(1: 2,500)$ for $1 \mathrm{~h}$. Protein bands were visualized using the Odyssey CLx Imaging System (LI-COR Biosciences). ImageJ software (National Institutes of Health) was used for quantitative analysis.

Cell transfection. To confirm the effects of MALAT1 knockdown on migration, MALAT1 gene expression was knocked down using siRNA. Cells $\left(5 \times 10^{5}\right)$ were transfected with $50 \mathrm{nM}$ siRNA-MALAT1 (si-MALAT1 forward, 5'-GGA AGUAAUUCA AGAUCAATT-3' and reverse, 5'-UUGAUCUUGAAUUACUUCCTT-3'; si-MALAT1-2 forward, 5'-GGGCUUCUCUUA ACAUUUAUU-3' and reverse, 5'-UAA AUGUUAAGAGAAGCCCUU-3'; or si-control forward, 5'-UUCUCCGAACGUGUCACGUTT-3' and reverse, 5'-ACGUGACACGUUCGGAGAATT-3') using Effectene transfection reagent (Qiagen $\mathrm{GmbH}$ ), according to the manufacturer's protocol. Following $24 \mathrm{~h}$ of transfection at $37^{\circ} \mathrm{C}$ in an incubator, cells were treated with $0.01 \mu \mathrm{M}$ TG for $24 \mathrm{~h}$. si-MALAT1 was selected for use in future experiments.

Statistical and bioinformatics analysis. Statistical analysis was performed using GraphPad Prism 7 (GraphPad Software, Inc.) and SPSS Statistics version 21 (IBM Corp.). All data are expressed as the mean \pm SD. Statistical differences between groups were determined using two-way ANOVA and corrected for multiple comparisons using Sidak statistical hypothesis test (Figs. 1, 3, 4D and E, 5B-F and 6A), one-way ANOVA and corrected for multiple comparisons using Dunnett's statistical 

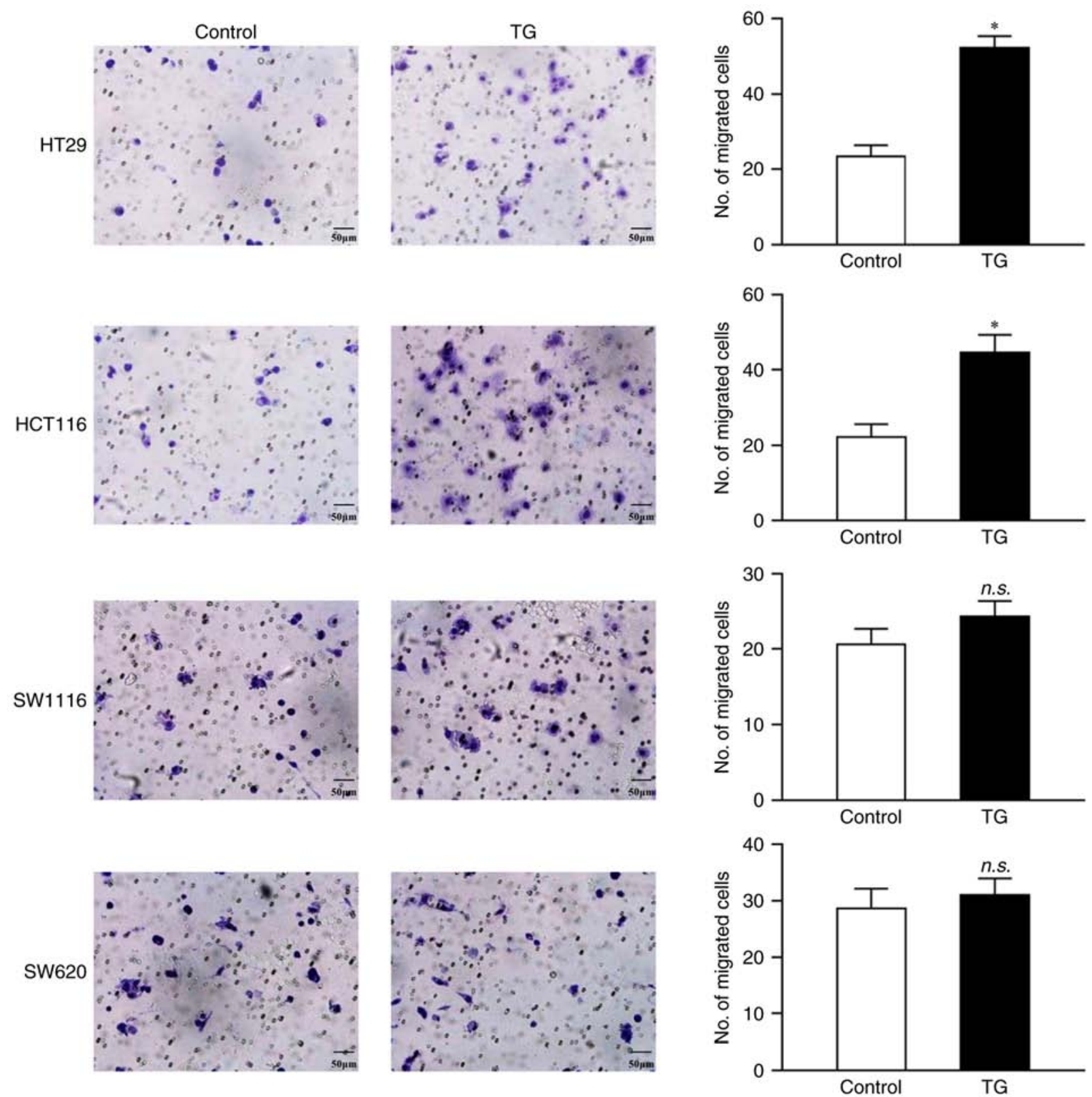

Figure 2. Effect of low dose TG treatment on human CRC cell migration. Migration assays were performed on the four CRC cell lines following treatment for $24 \mathrm{~h}$ with $0.01 \mu \mathrm{M}$ TG. Tests were performed in triplicate and data are presented as the mean $\pm \mathrm{SD}$. ${ }^{*} \mathrm{P}<0.05$. TG, thapsigargin; CRC, colorectal cancer.

hypothesis test (Fig. 4A and B), Student's t-tests (Fig. 2), and non-parametric Spearman's rank correlation coefficient (Fig. 7). $\mathrm{P}<0.05$ was considered to indicate a statistically significant difference. The binding site sequences were identified using bioinformatics analysis platform (the JASPAR 2018 database, http://jaspar.genereg.net/).

\section{Results}

Effect of TG on cell viability in the human CRC cell lines. The effect of TG $(0-10 \mu \mathrm{M})$ treatment for $24 \mathrm{~h}$ on the cell viability of CRC lines was determined (Fig. 1). Cell death was successfully induced by $0.1 \mu \mathrm{M}$ TG in HT29, HCT116 and SW1116 cell lines $(58.12 \pm 4.03,72.03 \pm 2.37$ and $63.59 \pm 5.7$, respectively, $\mathrm{P}<0.0001)$, but not in the SW620 cells $(96.84 \pm 3.92 ; \mathrm{P}=0.98)$. Cell death occurred at a higher rate when treated with $10 \mu \mathrm{M}$
TG in the HT29, HCT116, SW1116 and SW620 cells (6.59 \pm 0.31 , $17.72 \pm 1.31,26.55 \pm 1.1$ and 43.66 \pm 2.73 , respectively; $\mathrm{P}<0.0001$ ). Cell death was not induced by $0.01 \mu \mathrm{M}$ TG in all four CRC cell lines. Thus, $0.01 \mu \mathrm{M}$ TG was selected to use in subsequent studies (Fig. 1).

Effects of low dose TG on human CRC migration. Next, the effect of TG on CRC cell migration was investigated. Treatment with $0.01 \mu \mathrm{M}$ TG for $24 \mathrm{~h}$ increased cell migration in HT29 (52.33 \pm 3.06 vs. $23.33 \pm 3.05 ; \mathrm{P}=0.0003)$ and HCT116 $(44.67 \pm 4.73$ vs. $22.33 \pm 3.21 ; \mathrm{P}=0.0025)$ cells, but not in $\mathrm{SW} 1116$ $(24.33 \pm 2.08$ vs. $20.67 \pm 2.10 ; \mathrm{P}=0.097)$ or $\mathrm{SW620}(31.00 \pm 3.00$ vs. $28.67 \pm 3.51 ; \mathrm{P}=0.43$; Fig. 2 ) cells.

TG-induced cell migration is associated with increased expression levels of MALAT1. Following TG treatment, 


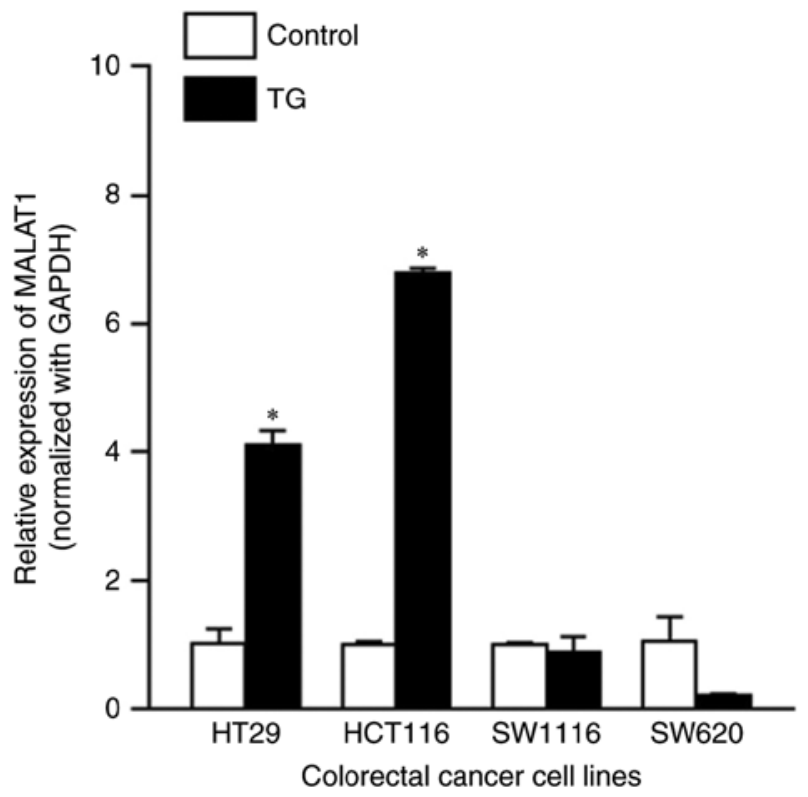

Figure 3. Effect of low dose TG treatment on MALAT1 expression levels in CRC. Long non-coding RNA MALAT1 expression was detected in CRC cell lines using reverse transcription-quantitative PCR following treatmen for $24 \mathrm{~h}$ with $0.01 \mu \mathrm{M}$ TG. The ratio of MALAT1/GAPDH was presented as induction (n-fold) relative to the control. Data are expressed as the mean \pm SD. ${ }^{*} \mathrm{P}<0.05$. TG, thapsigargin; MALAT1, metastasis-associated lung adenocarcinoma transcript $1 ; \mathrm{CRC}$, colorectal cancer.

MALAT1 expression levels were significantly increased in HT29 (4.11 \pm 0.22 vs. $1 \pm 0.23 ; \mathrm{P}<0.0001)$ and HCT116 (6.79 \pm 0.07 vs. $1 \pm 0.05 ; \mathrm{P}<0.0001)$ cells, but not in SW1116 (0.89 \pm 0.24 vs $1 \pm 0.03 ; \mathrm{P}=0.99)$ or $\mathrm{SW620}(0.23 \pm 0.02$ vs. $1 \pm 0.38 ; \mathrm{P}=0.002$; Fig. 3) cells.

Knockdown of MALAT1 reverses TG-induced cell migration. MALAT1 gene expression levels were knocked down using siRNA and rescue experiments of migration were subsequently performed to identify the role of MALAT1 in CRC. The expression levels of MALAT1 were significantly decreased by si-MALAT1 in HT29 [0.38 \pm 0.004 vs. $1 \pm 0.07$ (si-control group); $\mathrm{P}=0.0001]$ and HCT116 [0.37 \pm 0.010 vs. $1 \pm 0.03$ (si-control group); $\mathrm{P}<0.0001]$ cell lines (Fig. 4A and B). si-MALAT1-2 reduced MALAT1 expression levels in HCT116 cells [0.58 \pm 0.012 vs. $1 \pm 0.031$ (si-control group); $\mathrm{P}<0.0001]$, but not in HT29 cells $[1.17 \pm 0.003$ vs. $1 \pm 0.072$ (si-control group); $\mathrm{P}>0.05$; Fig. 4A and B]. Thus, si-MALAT1 was selected as the siRNA to use for subsequent experiments.

The knockdown of MALAT1 reversed TG-induced cell migration in HT29 [22.7 \pm 3.1 (si-control) vs. 41.3 \pm 4.2 (si-control and $\mathrm{TG}^{+}$); $\mathrm{P}=0.0002 ; 14.3 \pm 1.5$ (si-MALAT1) vs. 15.7 \pm 1.5 (si-MALAT1 and $\mathrm{TG}^{+}$); $\mathrm{P}=0.93$ ] and $\mathrm{HCT} 116$ $\left[18.0 \pm 2.6\right.$ (si-control) vs. 39.7 \pm 3.5 (si-control and $\mathrm{TG}^{+}$); $\mathrm{P}<0.0001 ; 12.7 \pm 1.5$ (si-MALAT1) vs. $14.0 \pm 1.0$ (si-MALAT1 and $\mathrm{TG}^{+}$); $\mathrm{P}=0.89$ ] cells (Fig. 4C-E).

Effects of TG on the expression levels of UPR-associated molecules in human CRC cell lines. To analyze the mechanism of TG-induced MALAT1 expression, the expression levels or activation of UPR-associated molecules (GRP78, XBP1s and XBP1u of the IRE1 signaling pathway, eIF2 $\alpha$, phospho-eIF $2 \alpha$,
ATF4 of the PERK signaling pathway, p90ATF6 and p50ATF6 of the ATF6 signaling pathway) were analyzed using western

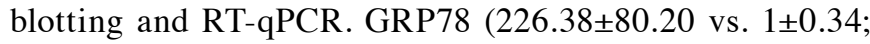
$\mathrm{P}=0.006), \mathrm{XBP} 1 \mathrm{~s}(21.95 \pm 11.98$ vs. $1 \pm 0.048 ; \mathrm{P}=0.0198), \mathrm{XBP} 1 \mathrm{u}$ (9.19 \pm 2.84 vs. $1 \pm 0.02 ; \mathrm{P}=0.0052), \mathrm{ATF} 4$ ( $3.12 \pm 1.12$ vs. $1 \pm 0.15$; $\mathrm{P}=0.0155)$ and $\mathrm{p} 90 \mathrm{ATF} 6(1.44 \pm 0.10$ vs. $1 \pm 0.004 ; \mathrm{P}=0.0017)$ protein expression levels were significantly increased in TG-treated HT29 cells compared with the control group, and TG treatment successfully induced the phosphorylation of eIF $2 \alpha(6.20 \pm 1.18$ vs. $1 \pm 0.030 ; \mathrm{P}<0.0001$; Fig. 5A-C). In TG-treated HCT116 cells, the expression levels of GRP78 $(9.00 \pm 4.55$ vs. $1 \pm 0.023 ; \mathrm{P}=0.0195), \mathrm{XBP} 1 \mathrm{~s}(13.89 \pm 1.70 \mathrm{vs}$. $1 \pm 0.07 ; \mathrm{P}=0.00031), \mathrm{XBP} 1 \mathrm{u}(1.84 \pm 0.53$ vs. $1 \pm 0.015 ; \mathrm{P}=0.024)$, ATF4 (3.55 \pm 0.66 vs. $1 \pm 0.15 ; \mathrm{P}=0.0017)$, p90ATF6 $(1.56 \pm 0.024$ vs. $1 \pm 0.004 ; \mathrm{P}<0.0001)$, p50ATF6 ( $1.63 \pm 0.018$ vs. $1 \pm 0.003$; $\mathrm{P}<0.0001)$ and phosphorylated eIF $2 \alpha(3.83 \pm 0.25$ vs. $1 \pm 0.017$; $\mathrm{P}<0.0001)$ were increased compared with the control group (Fig. 5A-C). In TG-treated SW1116 cells, the expression level of GRP78 (5.75 \pm 1.93 vs. $1 \pm 0.028 ; \mathrm{P}=0.008)$ was significantly increased compared with the control group (Fig. 5A-C). In TG-treated SW620 cells, the expression levels of GRP78 $(3.19 \pm 1.46$ vs. $1 \pm 0.094 ; \mathrm{P}=0.029)$, p90ATF6 (3.47 \pm 0.53 vs. $1 \pm 0.026 ; \mathrm{P}=0.0013)$ and p50ATF6 (1.29 \pm 0.017 vs. $1 \pm 0.007$; $\mathrm{P}<0.0001)$ were significantly increased compared with the control group (Fig. 5A-C).

Following TG treatment, GRP78 mRNA expression levels were significantly increased in HT29, HCT116, SW1116 and SW620 cells $(5.41 \pm 0.48,6.32 \pm 1.06,4.92 \pm 0.84$ and $1.97 \pm 0.25$, respectively; $\mathrm{P}<0.0001)$ compared with the control group (Fig. 5D). XBP1 mRNA expression levels were significantly increased in HT29 (1.73 \pm 0.08 vs. $1 \pm 0.096 ; \mathrm{P}=0.081)$ and HCT116 (2.04 \pm 0.49 vs. $1 \pm 0.05 ; \mathrm{P}=0.0034)$ cells compared with the control group (Fig. 5E) and ATF4 mRNA expression levels were significantly increased in HT29 (3.59 \pm 0.45 vs. $1 \pm 0.1 ; \mathrm{P}=0.0008)$, HCT116 (9.53 \pm 1.46 vs. $1 \pm 0.084 ; \mathrm{P}<0.0001)$ and SW1116 $(2.82 \pm 0.17$ vs. $1 \pm 0.053 ; \mathrm{P}=0.026)$ cells compared with the control group (Fig. $5 \mathrm{~F}$ ). These findings indicated that TG may induce the activation of the IRE1 and PERK UPR signaling pathways in HT29 and HCT116 cells; however, TG cannot induce the activation of these two signaling pathways in SW1116 and SW620 cells. Thus, it is hypothesized that TG-induced MALAT1 overexpression may be associated with the IRE1 and PERK signaling pathways.

Effects of UPR signaling pathway inhibitors on MALATI expression. To further confirm the hypothesis, the UPR signaling pathway inhibitors $4 \mu 8 \mathrm{C}$ (IRE1 pathway inhibitor), GSK2606414 (PERK pathway inhibitor) and AEBSF (ATF6 pathway inhibitor) were used to inhibit the activation of their respective signaling pathways. HCT116 cell were selected to carry out the rescue experiment because the IRE1, PERK and ATF6 signaling pathways were activated by TG (Fig. 5). TG-induced MALAT1 overexpression was significantly inhibited by $4 \mu 8 \mathrm{C}[6.79 \pm 0.072$ (control and $\left.\mathrm{TG}^{+}\right)$vs. $3.57 \pm 0.16\left(4 \mu 8 \mathrm{C}\right.$ and $\left.\left.\mathrm{TG}^{+}\right) ; \mathrm{P}<0.0001\right]$ and GSK2606414 [6.79 \pm 0.072 (control and $\mathrm{TG}^{+}$) vs. 3.24 \pm 0.21 $\left(G S K 2606414\right.$ and $\left.\left.\mathrm{TG}^{+}\right) ; \mathrm{P}<0.0001\right]$, but not by AEBSF $\left[6.79 \pm 0.072\right.$ (control and $\mathrm{TG}^{+}$) vs. 8.45 \pm 1.56 (AEBSF and $\left.\mathrm{TG}^{+}\right) ; \mathrm{P}<0.05$; Fig. 6A]. These data indicated that TG-induced MALAT1 expression was associated with the 
A

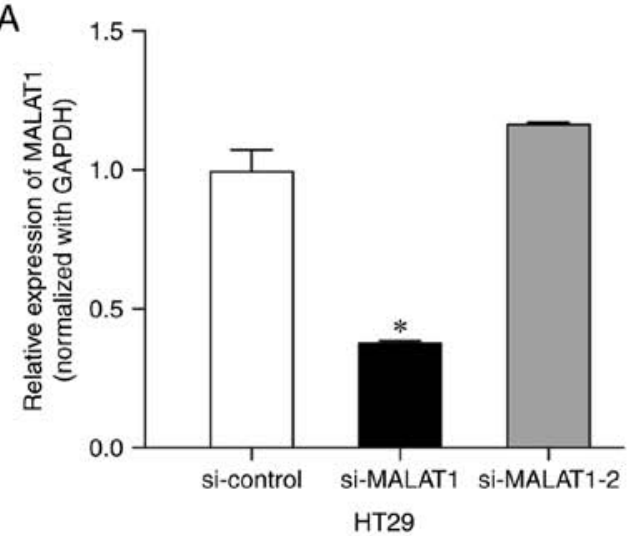

B

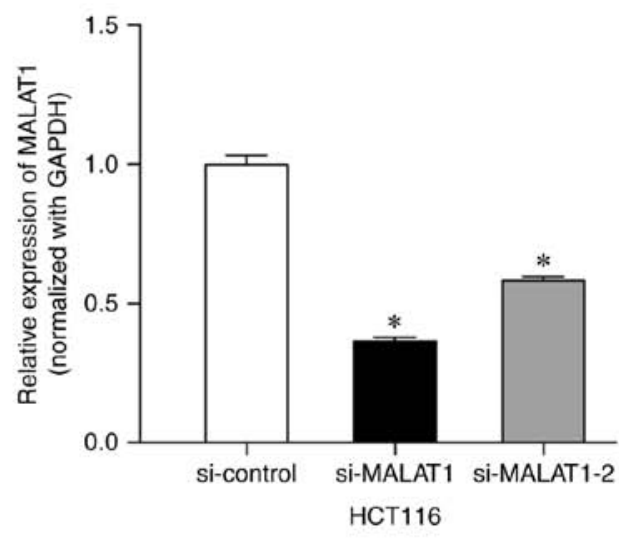

C
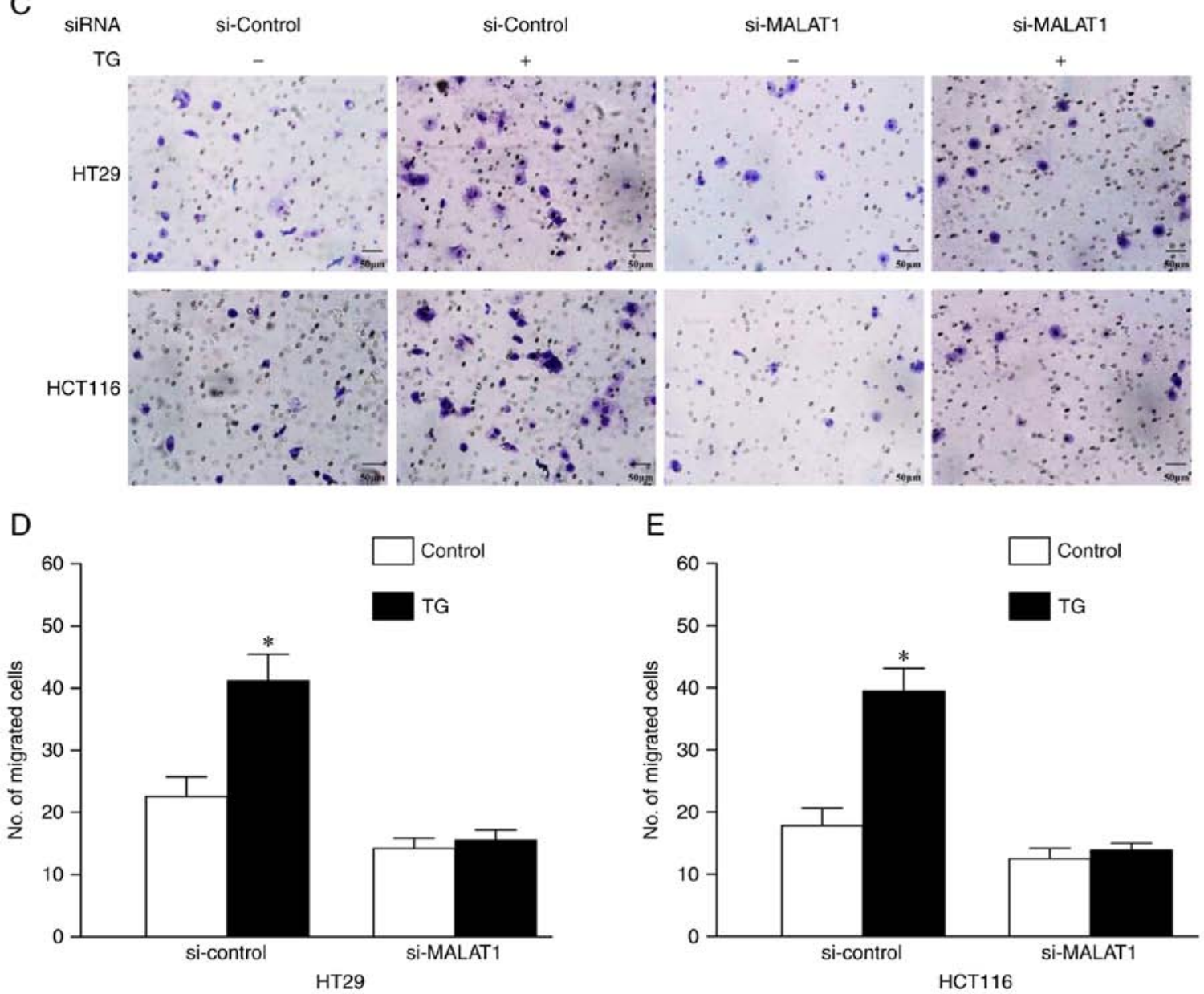

Figure 4. Effect of MALAT1 knockdown using siRNA on CRC cell migration. (A and B) Following $24 \mathrm{~h}$ transfection with two siRNAs, si-MALAT1 and si-MALAT1-2, the expression levels of MALAT1 were quantified in (A) HT29 and (B) HCT116 CRC cells. (C) Cell migration was analyzed in CRC cell lines following $24 \mathrm{~h}$ transfection with si-MALAT1 and subsequent treatment for $24 \mathrm{~h}$ with $0.01 \mu \mathrm{M}$ TG. (D) Number of migratory cells/field was counted in HT29 cells. (E) Number of migratory cells/field was counted in HCT116 cells. Data are expressed as the mean \pm SD. ${ }^{*} \mathrm{P}<0.05$. siRNA/si, small interfering RNA; MALAT1, metastasis-associated lung adenocarcinoma transcript 1; CRC, colorectal cancer; TG, thapsigargin.

IRE1 and PERK signaling pathways. To further analyze the molecular mechanisms of MALAT1 upregulation, the binding sites of XBP1 and ATF4, two transcription factors, were determined. The binding sites sequences of XBP1 and ATF4 were identified using the JASPAR 2018 database (http://jaspar. genereg.net/) and presented as position frequency matrices in humans (Fig. 6B and C). The promoter of MALAT1 was predicted by FPROM data sites (18), with 5 promoter regions (Fig. 6D) predicted. Near the promoter regions of MALAT1, three binding sites for XBP1 and one ATF4 binding site were successfully predicted (Fig. 6D).

Correlation analysis between XBP1, ATF4 and MALAT1 $m R N A$ expression levels in patients with $C R C$. XBP1, ATF4 and MALAT1 mRNA expression levels were detected by RT-qPCR and the correlation between the genes was analyzed using Spearman's rank correlation coefficient. The expression of IncRNA MALAT1 was positively correlated with XBP1 
A
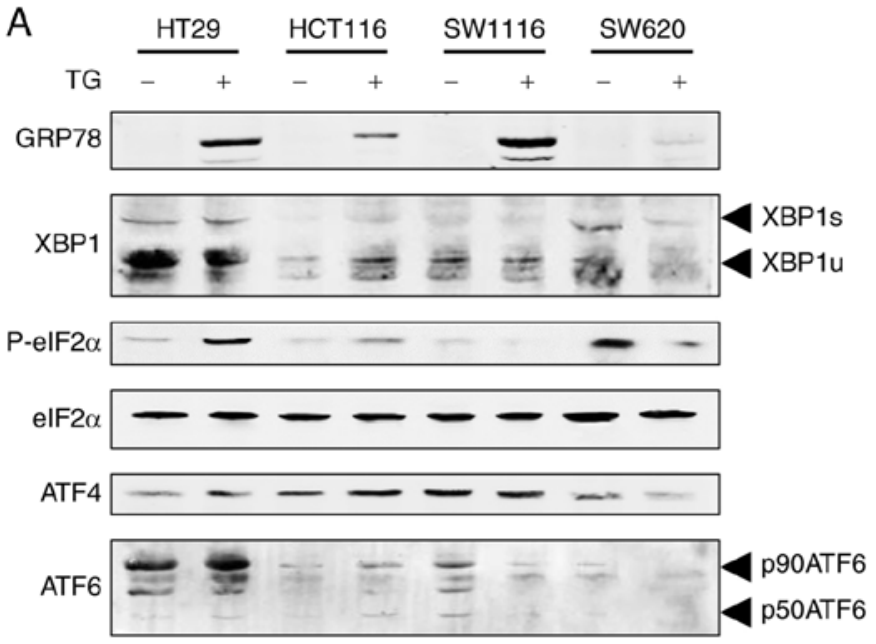

$\beta$-actin $\longrightarrow$

B
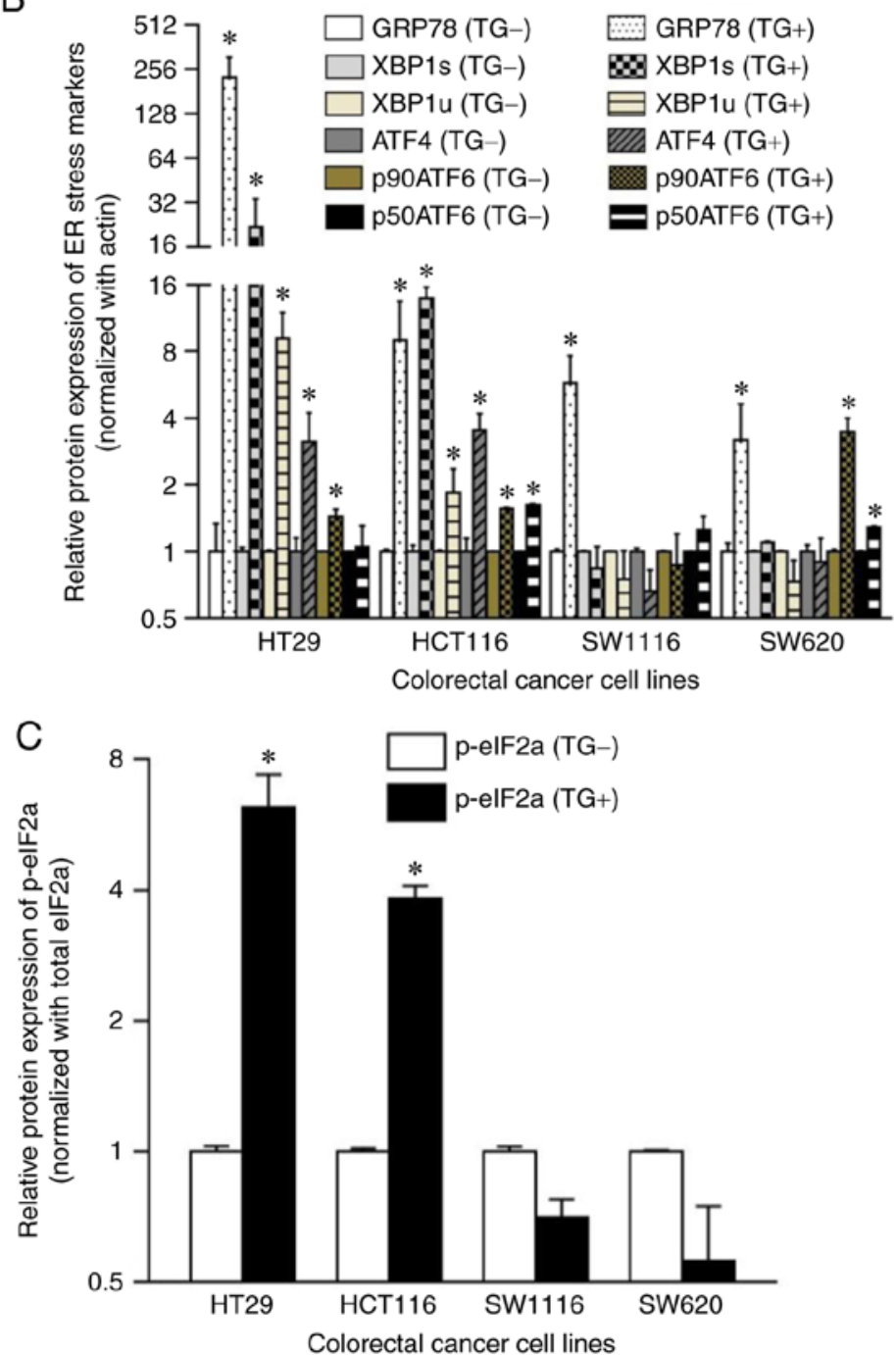

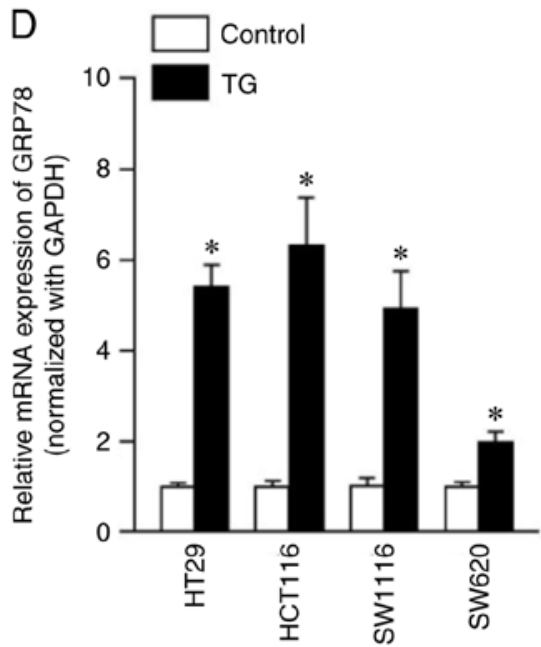

Colorectal cancer cell lines

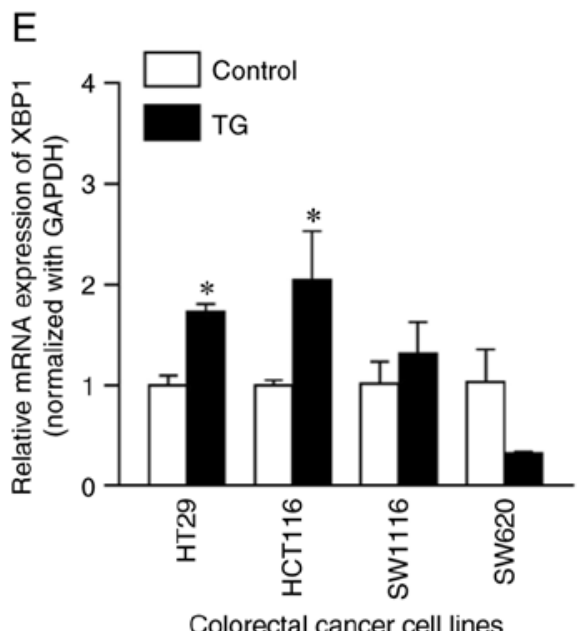

$\mathrm{F}$

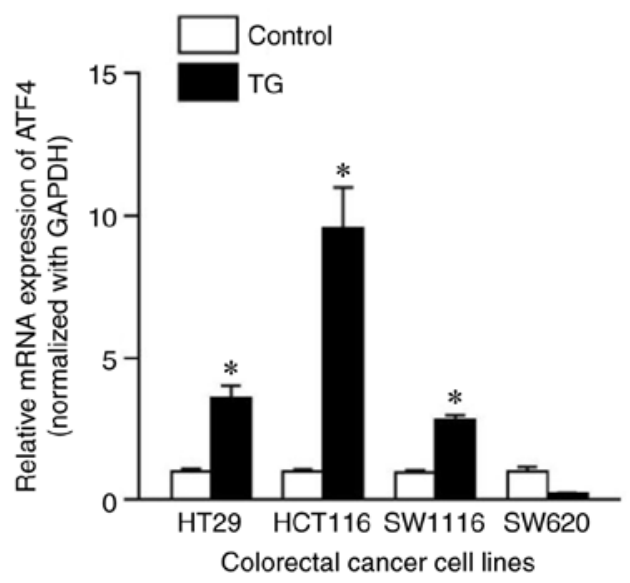

Figure 5. Effect of TG treatment on the expression levels of unfolded protein response-associated molecules in human CRC cell lines. (A) Western blot analysis of the expression levels of GRP78, XBP1s, XBP1u, ATF4, p90ATF6, p50ATF6, eIF2 $\alpha$, phosphorylated eIF2 $\alpha$ and $\beta$-actin in CRC cell lines with or without $24 \mathrm{~h}$ treatment with $0.01 \mu \mathrm{M}$ TG. (B) Protein expression levels of GRP78, XBP1s, XBP1u, ATF4, p90ATF6 and p50ATF6 were semi-quantified and the data was normalized to the loading control $\beta$-actin. Data are presented as the mean \pm SD. (C) Expression levels of phosphorylated eIF2 $\alpha$ were semi-quantified and the data was normalized to total eIF2 $\alpha$ expression levels. Data are presented as the mean \pm SD. (D-F) Following 24-h treatment with $0.01 \mu$ M TG, (D) GRP78, (E) XBP1 and (F) ATF4 mRNA expression levels were detected by reverse transcription quantitative-PCR. The ratios of GRP78/GAPDH, XBP1/GAPDH and ATF4/GAPDH were presented as induction (n-fold) relative to the control. Data are presented as the mean $\pm \mathrm{SD}$. "P $<0.05$. GRP78, glucose regulated protein 78; XBP1, X-box-binding protein 1; ATF, activating transcription factor; eIF2 $\alpha, \alpha$-subunit of eukaryotic initiation factor-2; TG, thapsigargin; CRC, colorectal cancer. 
A

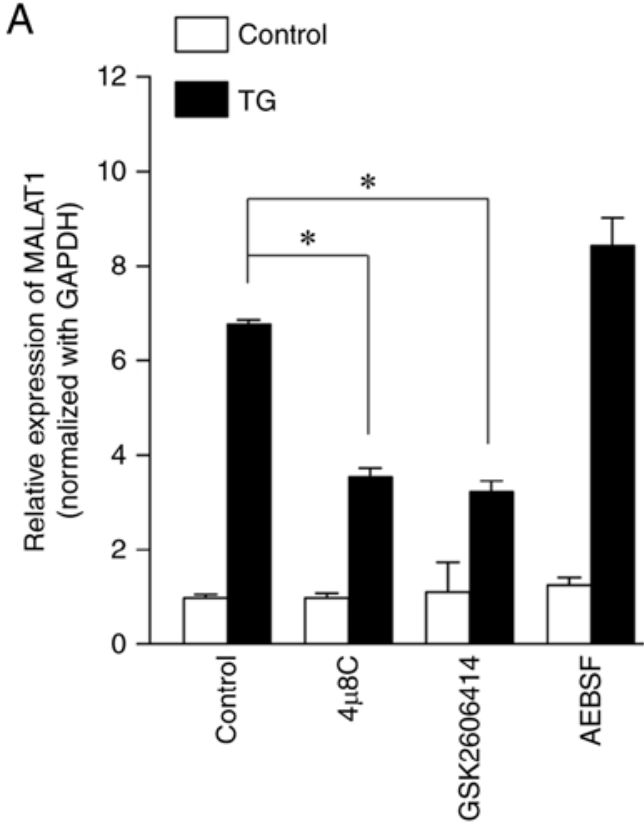

UPR signaling pathway inhibitors
$\mathrm{B}$

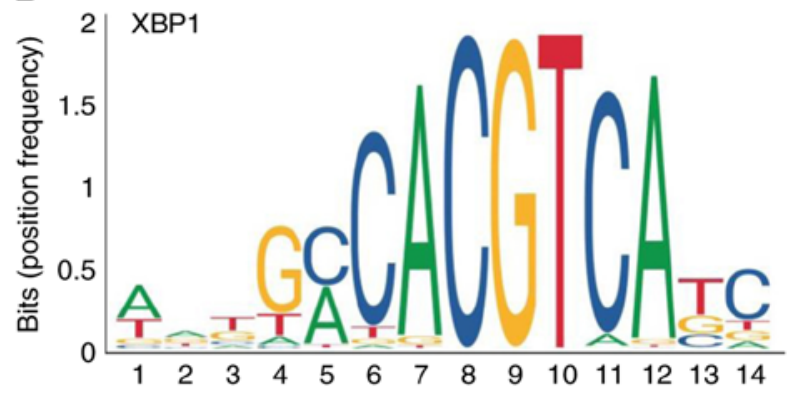

C

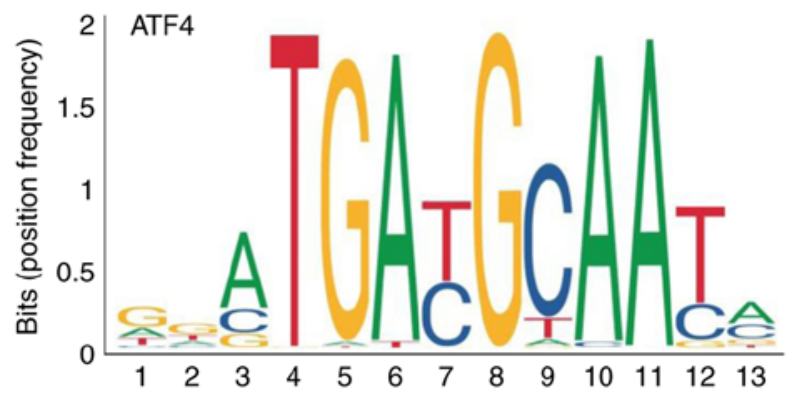

D
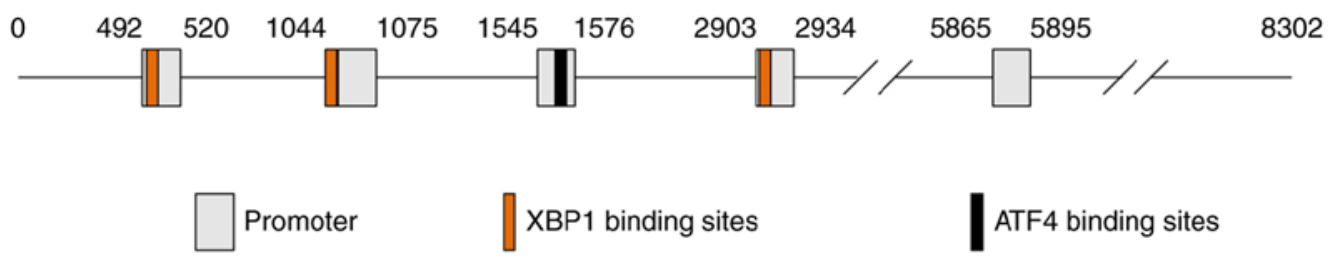

MALAT1

NR_144568.1

Figure 6. Effect of UPR signaling pathway inhibitors on MALAT1 expression levels and prediction of MALAT1 transcription regulation sites. (A) Effect of UPR signaling pathway inhibitors on MALAT1 expression levels. UPR signaling pathway inhibitors, $4 \mu 8 \mathrm{C}$ (IRE1/XBP1 pathway inhibitor; $1 \mu \mathrm{M} ; 24 \mathrm{~h}$ ), GSK2606414 (PERK/eIF2 $\alpha /$ ATF4 pathway inhibitor; $1 \mu \mathrm{M} ; 24 \mathrm{~h}$ ) and AEBSF (ATF6 pathway inhibitor; $0.3 \mu \mathrm{M} ; 24 \mathrm{~h}$ ), were used to inhibit the activation of their respective signaling pathways in HCT116 cells. Expression levels of long non-coding RNA MALAT1 were subsequently detected using reverse transcription quantitative-PCR. The ratio of MALAT1/GAPDH was presented as induction (n-fold) relative to the control. Data are expressed as the mean \pm SD. "P $<0.05$. (B and C) The binding sites sequences of (B) XBP1 and (C) ATF4 transcription factors were presented as the position frequency matrices in humans. (D) MALAT1 promoter regions (gray frame; predicted by FPROM data sites) and binding sites of XBP1 (orange frame) and ATF4 (black frame) are presented. UPR, unfolded protein response; MALAT1, metastasis-associated lung adenocarcinoma transcript 1; IRE1, inositol-requiring enzyme 1; XBP1, X-box-binding protein 1; PERK, protein kinase R (PKR)-like ER kinase; eIF2 $\alpha, \alpha$-subunit of eukaryotic initiation factor-2; ATF, activating transcription factor.

$\left(\mathrm{R}^{2}=0.79 ; \mathrm{P}<0.0001 ;\right.$ Fig. 7A) and ATF4 $\left(\mathrm{R}^{2}=0.57 ; \mathrm{P}<0.0001\right.$; Fig. 7B) in CRC tissue samples. Thus, the relationship between MALAT1 expression and ER stress was further verified.

The overall activation of the ER stress pathway in the four CRC cell lines was summarized in a schematic diagram (Fig. 8A) and the hypothesized mechanism of TG-induced increases in lncRNA MALAT1 expression levels is presented in Fig. 8B.

\section{Discussion}

In the present study, it was demonstrated that: i) Low dose TG induced migration in HT29 and HCT116 cells, but not SW1116 and SW620 cells, the effect of which was linked to the enhanced expression levels of MALAT1; ii) the knockdown of MALAT1 using siRNA reversed this TG-induced promotion of cell migration; iii) TG-induced MALAT1 expression was associated with the activation of the IRE1/XBP1 and PERK/eIF2 $\alpha /$ ATF4 signaling pathways; and iv) the XBP1 and ATF4 binding sites were found within MALAT1 gene promoter regions. To the best of our knowledge, this study was the first to report that lncRNA MALAT1 expression levels were regulated by the IRE1 signaling pathway of the UPR in CRC.

The ER stress activation and the unfolded protein response (UPR) triggers, response to cancer cellular stress conditions including glucose deprivation, hypoxia, proteins folding and secretion of proteins, the denouement is either the restoration of homeostasis or cell death (19). Some studies ascertained that ER stress was correction with CRC progression. ER stress-related ATF6 upregulated cancerous inhibitor of protein phosphatase $2 \mathrm{~A}$ contributing to poor prognosis of colon cancer (20). ATF6 induced intestinal dysbiosis to promote colorectal tumorigenesis through innate immune response (21).

The oncogenic roles of XBP1 in CRC and other types of cancer have been reported in numerous studies; the activation of the IRE1/XBP1 pathway induced cell proliferation and invasion in CRC (3), whereby XBP1 was demonstrated to promote 

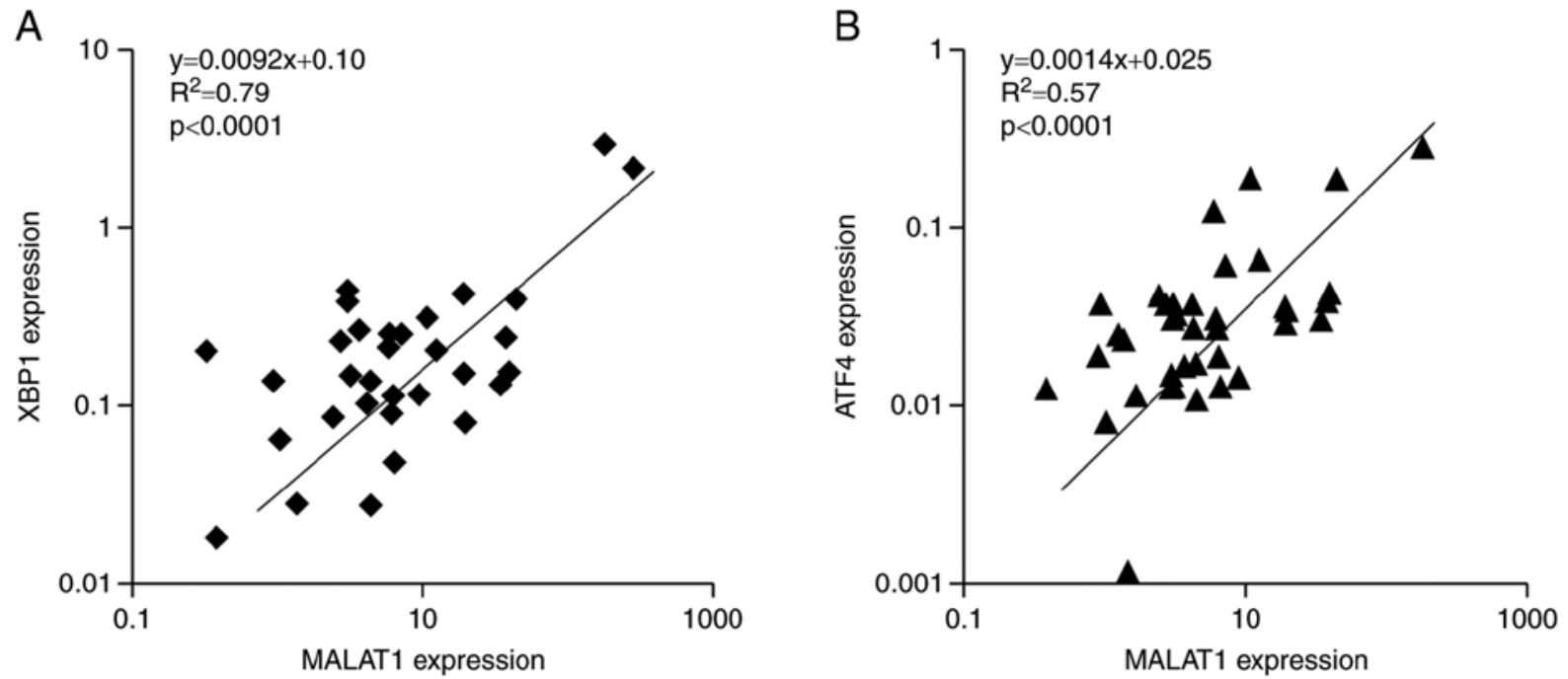

Figure 7. Correlation analysis between XBP1, ATF4 and MALAT1 expression levels in patients with colorectal cancer. (A and B) Expression levels of (A) XBP1, (B) ATF4 and MALAT1 were detected by reverse transcription quantitative-PCR. The correlation and P-values were analyzed using Spearman's rank correlation coefficient. MALAT1, metastasis-associated lung adenocarcinoma transcript 1; XBP1, X-box-binding protein 1; ATF, activating transcription factor.

A

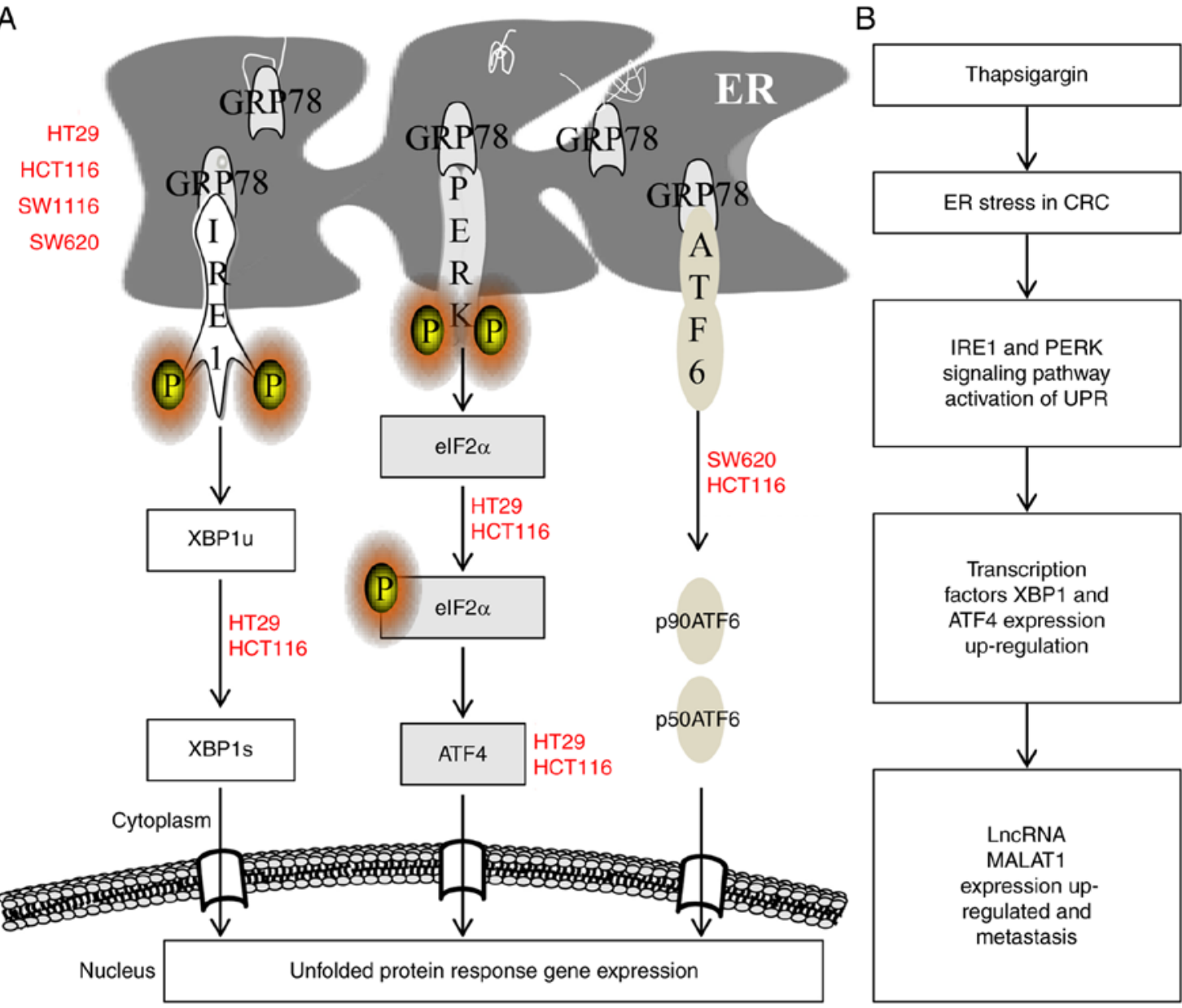

Figure 8. Schematic diagrams of endoplasmic reticulum stress pathways and hypothesized mechanism. (A) Schematic diagram of endoplasmic reticulum stress pathways in human colorectal cancer cell lines. (B) Schematic diagram presenting the hypothesized mechanism of TG-induced increased expression levels of long non-coding RNA MALAT1. TG, thapsigargin; MALAT1, metastasis-associated lung adenocarcinoma transcript 1.

CRC invasion through VEGFR2 (22). In prostate cancer, the IRE1/XBP1 signaling pathway promoted carcinogenesis by activating c-Myc signaling (23); in oral squamous cell carcinoma, XBP1 promoted cancer invasion and it was associated 
with poor prognosis (24); in breast cancer, the expression levels of XBP1s in the nucleus were correlated with shorter survival (25); whereas in ovarian cancer, the IRE1/XBP1 signaling pathway controlled T-cell functions, thus, mediating ER stress or targeting the IRE1/XBP1 pathway may restore the antitumor ability of T-cells (26). In addition, XBP1 positively regulated the cytolytic activity of human natural killer cells against leukemia cells (27); in hepatocellular carcinoma, the IRE1/XBP1 pathway controlled the expression of interleukin-6 (IL-6) and promoted hepatocarcinoma progression (28); and in oropharyngeal carcinoma without papillomavirus, the IRE1/XBP1 pathway induced resistance to radiotherapy by mediating IL-6 production (29). Thus, the transcription factor XBP1 may be a potential target to mediate tumor immunology and block cancer progression.

ATF4 has been observed to serve important roles in ER stress-induced apoptosis (30) and radiotherapy (31) or chemotherapy sensitivity (32). In CRC cells, the activation of the PERK/ATF4 signaling pathway promoted resistance to 5-fluorouracil (33) and increased expression levels of ATF4 were associated with glucose deprivation-induced chemoresistance (34). In prostate cancer, ATF4 protein expression levels were increased in the cancer tissue compared with benign prostate tissue (35) and similarly, in breast cancer, ATF4 expression levels were increased in HER2 ${ }^{+}$breast cancer, which promoted cell migration through the activation of zinc finger E-box binding homeobox 1 (ZEB1) and the downregulation of E-cadherin (36). ATF4 was associated with cell cycle progression in estrogen receptor negative breast cancer, which was due to its regulation over the GSK $3 \beta / \beta$-catenin/cyclin D1 pathway (37). Thus, suggesting that the transcription factor ATF4 may be associated with cancer progression through regulation of the cell cycle and cell migration.

Overall, the results of the present study indicated that low dose TG may promote CRC cell migration by upregulating the expression levels of IncRNA MALAT1; and the TG-induced increased expression levels of MALAT1 were associated with the activation of the IRE1/XBP1 and PERK/eIF2 $\alpha /$ ATF4 signaling pathways. The XBP1 and ATF4 binding sites were predicted to be located in the MALAT1 gene promoter regions; however, the direct interaction between MALAT1 and XBP1 or ATF4 was not verified in this study and will require further investigation in the future. In conclusion, ER stress may provide reasoning for the upregulated MALAT1 expression and metastasis observed in CRC, and ER stress-associated genes, especially XBP1 and ATF4, may represent potential targets for controlling metastasis in CRC.

\section{Acknowledgements}

The authors thank Professor Xiaofeng Sun and Professor Jun Yu for providing cells and technical support.

\section{Funding}

The study was supported by The National Natural Science Foundation of China (grant no. 81572758), The Natural Science Foundation of Hebei (grant no. H2017206286), The Foundation for Distinguished Young Talents in Higher Education of Hebei (grant no. BJ2018042), The International Science and Technology Cooperation Program of China (grant no. 2014DFA31150), the Latitudinal Projects Foundation from Hebei province (grant nos. CY201614, zh2018002 and 162777271) and The Spark Program of the First Hospital of Hebei Medical University (grant no. XH201701).

\section{Availability of data and materials}

The binding site sequences analyzed in the present study are publicly available from the JASPAR 2018 database (http://jaspar.genereg.net/).

\section{Authors' contributions}

$\mathrm{XJ}$ and $\mathrm{ZZ}$ conceived and designed the experiments. DL, WY, GW, JL, YL and XS performed the experiments. YW, CZ and JL collected and analyzed the data. XJ and ZZ interpreted the findings and wrote the manuscript. All authors read and approved the manuscript and agree to be accountable for all aspects of the research in ensuring that the accuracy or integrity of any part of the work are appropriately investigated and resolved.

\section{Ethics approval and consent to participate}

The present study was performed in accordance with standard guidelines and was approved by the Ethics Committee of The First Hospital of Hebei Medical University (no. 2016004).

\section{Patient consent for publication}

All patients written informed consent prior to the study, and all identifying information (including names, initials, date of birth or hospital numbers) was removed.

\section{Competing interests}

The authors declare that they have no competing interests.

\section{References}

1. Bray F, Ferlay J, Soerjomataram I, Siegel RL, Torre LA and Jemal A: Global cancer statistics 2018: GLOBOCAN estimates of incidence and mortality worldwide for 36 cancers in 185 countries. CA Cancer J Clin 68: 394-424, 2018.

2. Derry MM, Raina K, Agarwal R and Agarwal C: Characterization of azoxymethane-induced colon tumor metastasis to lung in a mouse model relevant to human sporadic colorectal cancer and evaluation of grape seed extract efficacy. Exp Toxicol Pathol 66: 235-242, 2014.

3. Jin C, Jin Z, Chen NZ, Lu M, Liu CB, Hu WL and Zheng CG: Activation of IRE1alpha-XBP1 pathway induces cell proliferation and invasion in colorectal carcinoma. Biochem Biophys Res Commun 470: 75-81, 2016.

4. Cox JS and Walter P: A novel mechanism for regulating activity of a transcription factor that controls the unfolded protein response. Cell 87: 391-404, 1996.

5. Xi J, Chen Y, Huang S, Cui F and Wang X: Suppression of GRP78 sensitizes human colorectal cancer cells to oxaliplatin by downregulation of CD24. Oncol Lett 15: 9861-9867, 2018.

6. Mujcic H, Nagelkerke A, Rouschop KM, Chung S, Chaudary N, Span PN, Clarke B, Milosevic M, Sykes J, Hill RP, et al: Hypoxic activation of the PERK/eIF2a arm of the unfolded protein response promotes metastasis through induction of LAMP3. Clin Cancer Res 19: 6126-6137, 2013. 
7. Limia CM, Sauzay C, Urra H, Hetz C, Chevet E and Avril T: Emerging roles of the endoplasmic reticulum associated unfolded protein response in cancer cell migration and invasion. Cancers (Basel) 11: pii: E631, 2019.

8. Vieyra A, Mintz E, Lowe $\mathrm{J}$ and Guillain $\mathrm{F}: \mathrm{Ca}^{2+}$ binding to sarcoplasmic reticulum ATPase phosphorylated by Pi reveals four thapsigargin-sensitive $\mathrm{Ca}^{2+}$ sites in the presence of ADP. Biochim Biophys Acta 1667: 103-113, 2004.

9. Ji Q, Cai G, Liu X, Zhang Y, Wang Y, Zhou L, Sui H and Li Q: MALAT1 regulates the transcriptional and translational levels of proto-oncogene RUNX2 in colorectal cancer metastasis. Cell Death Dis 10: 378, 2019.

10. Barbagallo C, Brex D, Caponnetto A, Cirnigliaro M Scalia M, Magnano A, Caltabiano R, Barbagallo D, Biondi A Cappellani A, et al: LncRNA UCA1, Upregulated in CRC biopsies and downregulated in serum exosomes, controls mRNA expression by RNA-RNA interactions. Mol Ther Nucleic Acids 12: 229-241, 2018.

11. Wang $\mathrm{C}$, Zhang Q, Hu Y, Zhu J and Yang J: Emerging role of long non-coding RNA MALAT1 in predicting clinical outcomes of patients with digestive system malignancies: A meta-analysis. Oncol Lett 17: 2159-2170, 2019.

12. Li P, Zhang X, Wang H, Wang L, Liu T, Du L, Yang Y and Wang C: MALAT1 is associated with poor response to oxaliplatin-based chemotherapy in colorectal cancer patients and promotes chemoresistance through EZH2. Mol Cancer Ther 16: 739-751, 2017.

13. Sun Z, Ou C, Liu J, Chen C, Zhou Q, Yang S, Li G, Wang G, Song J, Li Z, et al: YAP1-induced MALAT1 promotes epithelial-mesenchymal transition and angiogenesis by sponging miR-126-5p in colorectal cancer. Oncogene 38: 2627-2644, 2019

14. Bhattacharyya S and Vrati S: The Malat1 long non-coding RNA is upregulated by signalling through the PERK axis of unfolded protein response during flavivirus infection. Sci Rep 5: 17794, 2015.

15. Jiang $X$, Kanda $T$, Nakamoto $S$, Miyamura $T, W u ~ S$ and Yokosuka O: Involvement of androgen receptor and glucose-regulated protein $78 \mathrm{kDa}$ in human hepatocarcinogenesis. Exp Cell Res 323: 326-336, 2014.

16. Livak KJ and Schmittgen TD: Analysis of relative gene expression data using real-time quantitative PCR and the 2(-Delta Delta C(T)) method. Methods 25: 402-408, 2001.

17. Jiang $X$, Kanda $T$, Nakamoto $S$, Haga $Y$, Sasaki $R$, Nakamura M, Wu S, Mikata R and Yokosuka O: Knockdown of glucose-regulated protein 78 enhances poly(ADP-ribose) polymerase cleavage in human pancreatic cancer cells exposed to endoplasmic reticulum stress. Oncol Rep 32: 2343-2348, 2014

18. Solovyev VV, Shahmuradov IA and Salamov AA: Identification of promoter regions and regulatory sites. Methods Mol Biol 674: 57-83, 2010.

19. Wang Y, Wang JH,Zhang XL, Wang XLand Yang L: Endoplasmic reticulum chaperone glucose-regulated protein 78 in gastric cancer: An emerging biomarker. Oncol Lett 15: 6087-6093, 2018

20. Liu CY, Hsu CC, Huang TT, Lee CH, Chen JL, Yang SH, Jiang JK, Chen WS, Lee KD and Teng HW: ER stress-related ATF6 upregulates CIP2A and contributes to poor prognosis of colon cancer. Mol Oncol 12: 1706-1717, 2018.

21. Coleman OI, Lobner EM, Bierwirth S, Sorbie A, Waldschmitt N, Rath E, Berger E, Lagkouvardos I, Clavel T, McCoy KD, et al: Activated ATF6 induces intestinal dysbiosis and innate immune response to promote colorectal tumorigenesis. Gastroenterology 155: 1539-1552.e12,2018.

22. Mhaidat NM, Alzoubi KH and Abushbak A: X-box binding protein 1 (XBP-1) enhances colorectal cancer cell invasion. J Chemother 27: 167-173, 2015.
23. Sheng X, Nenseth HZ, Qu S, Kuzu OF, Frahnow T, Simon L, Greene S, Zeng Q, Fazli L, Rennie PS, et al: IRE1a-XBP1s pathway promotes prostate cancer by activating c-MYC signaling. Nat Commun 10: 323, 2019.

24. Sun Y, Jiang F, Pan Y, Chen X, Chen J, Wang Y, Zheng X and Zhang J: XBP1 promotes tumor invasion and is associated with poor prognosis in oral squamous cell carcinoma. Oncol Rep 40: 988-998, 2018

25. Wang M, Ruan S, Ming J and Dong F: Nuclear expression of $\mathrm{XBP} 1 \mathrm{~s}$ is correlated with breast cancer survival: A retrospective analysis based on tissue microarray. Onco Targets Ther 10: 5927-5934, 2017.

26. Song M, Sandoval TA, Chae CS, Chopra S, Tan C, Rutkowski MR, Raundhal M, Chaurio RA, Payne KK, Konrad C, et al: IRE1a-XBP1 controls $\mathrm{T}$ cell function in ovarian cancer by regulating mitochondrial activity. Nature 562: 423-428, 2018.

27. Wang Y,Zhang Y, YiP, Dong W, Nalin AP, Zhang J,Zhu Z, Chen L, Benson DM, Mundy-Bosse BL, et al: The IL-15-AKT-XBP1s signaling pathway contributes to effector functions and survival in human NK cells. Nat Immunol 20: 10-17, 2019.

28. Fang P, Xiang L, Huang S, Jin L, Zhou G, Zhuge L, Li J, Fan H, Zhou L, Pan C and Zheng Y: IRE1a-XBP1 signaling pathway regulates IL-6 expression and promotes progression of hepatocellular carcinoma. Oncol Lett 16: 4729-4736, 2018

29. Lyu X, Zhang M, Li G, Cai Y, Li G and Qiao Q: Interleukin-6 production mediated by the IRE1-XBP1 pathway confers radioresistance in human papillomavirus-negative oropharyngeal carcinoma. Cancer Sci 110: 2471-2484, 2019.

30. Chakraborty S, Ghosh S, Banerjee B,Santra A,Bhat J, Adhikary A, Chatterjee S, Misra AK and Sen PC: Mephebrindole, a synthetic indole analog coordinates the crosstalk between p38MAPK and eIF2a/ATF4/CHOP signalling pathways for induction of apoptosis in human breast carcinoma cells. Apoptosis 21: 1106-1124, 2016.

31. Zong Y, Feng S, Cheng J, Yu C and Lu G: Up-regulated ATF4 expression increases cell sensitivity to apoptosis in response to radiation. Cell Physiol Biochem 41: 784-794, 2017.

32. Notte A, Rebucci M, Fransolet M, Roegiers E, Genin M, Tellier C, Watillon K, Fattaccioli A, Arnould T and Michiels C: Taxol-induced unfolded protein response activation in breast cancer cells exposed to hypoxia: ATF4 activation regulates autophagy and inhibits apoptosis. Int J Biochem Cell Biol 62: $1-14,2015$.

33. Shi Z, Yu X, Yuan M,Lv W, Feng T, Bai R and Zhong H: Activation of the PERK-ATF4 pathway promotes chemo-resistance in colon cancer cells. Sci Rep 9: 3210, 2019.

34. Hu YL, Yin Y, Liu HY, Feng YY, Bian ZH, Zhou LY, Zhang JW, Fei BJ, Wang YG and Huang ZH: Glucose deprivation induces chemoresistance in colorectal cancer cells by increasing ATF4 expression. World J Gastroenterol 22: 6235-6245, 2016.

35. Pällmann N, Livgård $\mathrm{M}$, Tesikova $\mathrm{M}$, Zeynep Nenseth $\mathrm{H}$, Akkus E, Sikkeland J, Jin Y, Koc D, Kuzu OF, Pradhan M, et al: Regulation of the unfolded protein response through ATF4 and FAM129A in prostate cancer. Oncogene 38: 6301-6318, 2019.

36. Zeng P, Sun S, Li R, Xiao ZX and Chen H: HER2 upregulates ATF4 to promote cell migration via activation of ZEB1 and downregulation of E-cadherin. Int J Mol Sci 20: 2223, 2019.

37. Gao S, Ge A, Xu S, You Z, Ning S, Zhao Y and Pang D: PSAT1 is regulated by ATF4 and enhances cell proliferation via the GSK3 $\beta / \beta$-catenin/cyclin D1 signaling pathway in ER-negative breast cancer. J Exp Clin Cancer Res 36: 179, 2017.

This work is licensed under a Creative Commons Attribution-NonCommercial-NoDerivatives 4.0 International (CC BY-NC-ND 4.0) License. 